\title{
Pattern of fiber intake in different socio-demographic settings among elderly in Jakarta, Indonesia and its associated factors
}

Received 16 January 2021 Accepted 24 January 2021

Link to DOI:

10.25520/WNJ.V04.i2.0002

Journal Website: www.worldnutrijournal.org
Nanda Fauziyana ${ }^{1}$, Erfi Prafiantini ${ }^{1}$, Novi Silvia Hardiany ${ }^{2}$

1. Department of Nutrition, Faculty of Medicine, Universitas Indonesia-Dr. Cipto Mangunkusumo General Hospital, Jakarta, Indonesia

2. Department of Biochemistry \& Molecular Biology, Faculty of Medicine, Universitas IndonesiaDr. Cipto Mangunkusumo General Hospital, Jakarta, Indonesia

\begin{abstract}
Introduction Despite many health benefits from dietary fiber, inadequate intake is prevalent among elderly population. This study aims to obtain the pattern of fiber intake in different sociodemographic backgrounds among elderly in Jakarta area, Indonesia and its' associated factors.

Methods: A cross-sectional study was conducted among elderly aged $\geq 60$ years in 5 community health center across Jakarta province. A total of 126 elderly were interviewed using two nonconsecutive 24-h dietary recall methods to obtain dietary intake data. Socio-demographic backgrounds on age, sex, education, income, marital status, and energy intake were assessed using structured questionnaire. Mann-Whitney or independent t-test was performed to measure the different of fiber intake in each socio-demographic variable. Linear regression test was performed to analyze the variables that associated with fiber intake.

Results: Majority of $98.4 \%$ of elderly have total fiber intake $<80 \%$ of Indonesian Recommended Dietary Allowance (RDA) with average intake of $6.6 \mathrm{~g} / \mathrm{d}$. Lower fiber intake was significantly found in females, widowed/separated, have lower education and income, and have inadequate energy intake. Factors associated with total fiber intake were income (adjusted $\beta=0.20, p=0.01$ ) and energy intake adequacy (adjusted $\beta=0.65 \mathrm{p}=0.00$ ).

Conclusion: Fiber intake among elderly in urban area is inadequate and the pattern was worse in the low socio-demographic settings. By this finding, it is important to give priority to the socially disadvantages group when formulating nutrition intervention policy in this population setting.

Keywords dietary fiber, socio-demographic, elderly, Jakarta, Indonesia
\end{abstract}




\section{Introduction}

Numbers of elderly around the world are rapidly growing. The share on prevalence of this population in the low-middle income country like Indonesia was among the highest. Ministry of Health Indonesia reported that there were $9.03 \%$ elderly live in Indonesia in 2017 and projected to reach about $12.9 \%$ in $2030 .{ }^{1}$ As the capital city of Indonesia, Jakarta province has the second highest life expectancy among other province which was 73.56 years in $2015 .^{2}$ In the other hand, social inequity gap in this area was high. Indonesian National Statistic Agencies reported that income per capita inequity in Jakarta was higher than the national number since 2014 indicated by Gini coefficient that accounted as much as 0.39 in $2018 .^{3}$ Due to many factors affecting health status of elderly that contributed not only physiological factors, but also social determinants, social inequity in urban area could affect health status of elderly living in this area. $^{4}$

Dietary factors play significant roles in the prevention and management of diseases among elderly population. Due to gradual changes in metabolic and physiological function in older age, higher risk to chronic diseases among elderly occurs. Common conditions such as hearing loss, osteoarthritis, lung disease, type- 2 diabetes, and neuro function decline were prevalent. ${ }^{5}$ In the other hand, dietary fiber intake has been studied to be part of important components in balance and healthy diet practices that support the prevention of chronic diseases among elderly population. Consumption of dietary fiber proven to be associated with the lower risk to cardiovascular risk factors such as type-2 diabetes and chronic kidney disease. ${ }^{6}$ In addition, lower risk to depression, constipation, and obesity were also observed to be associated with high intake in dietary fiber in daily basis. ${ }^{7,8}$

The role of dietary fiber in body function was crucial due to its physicochemical components that take part in the digestion processing time and viscosity. The function includes as an effective stool bulkers, modulator of blood glucose level, and lowering blood cholesterol levels. ${ }^{9}$ Sources of dietary fiber are commonly found in cereals, vegetables, fruits, and nuts with various range of fiber content. Food sources such as corn, wheat (whole grain), and soy were reported to have high fiber content with more than $10 \mathrm{~g}$ fiber in $100 \mathrm{~g}$ of edible portion. While among fruits and vegetables group that has high fiber content in $100 \mathrm{~g}$ edible portion were bitter gourd (16.6 g), beetroot (7.8), eggplant (6.6), kiwi (3.39), pear (3.0), and strawberry (2.2). ${ }^{10}$

In contrast with the important role of dietary fiber in many metabolic processes, inadequate intake of this nutrient component was found to be prevalent especially among elderly population. Indonesian Dietary Guideline (IDG) gives a recommendation of fiber intake about $25 \mathrm{~g} /$ day for men and $22 \mathrm{~g}$ /day for women aged $65-80$ years old. ${ }^{11}$ However, previous studies among outpatient elderly in multicenter study and urban elderly in Yogyakarta province showed the average intake of fiber intake was $9 \mathrm{~g} /$ day. ${ }^{12,13}$ This number was contributed only around $37 \%$ of the Indonesian Recommended Dietary Allowance (RDA). Factors such as education and income have been reported to be correlated with the intake of fiber among elderly. ${ }^{14-16}$ However the data on pattern of this food group intake in different socio-demographic settings among elderly in low middle income settings such as Indonesia is still lacking. Information on the fiber intake based on socio-demographic and economic backgrounds are needed to support development that targeted elderly population with specific and appropriate strategies needed. Therefore, this study was conducted to obtain the profile of fiber intake among urban elderly in different socio-demographic factors in Jakarta, Indonesia.

\section{Methods}

\section{Subject and study design}

The study was designed as a cross-sectional study and participants were recruited from the sub-district community health center. The selection of subjects using community health center was on the basis of that the community health center as the first front line of National Health Insurance (NHI/JKN) program. Thus, elderly that become the member of the program should have register and have regular check up in this facility. ${ }^{17}$ We selected five subdistrict level of health center (Tanjung Priok, 
Palmerah, Johar Baru, Matraman, Jagakarsa) from five urban municipalities based on cluster sampling method.

Participants' recruitment and screening were conducted from July - August 2020 that based on the following criteria: aged $\geq 60$ years, residents of DKI Jakarta, and able to follow study protocols. Screening were conducted among 450 elderly from five community health center and 138 subjects were selected, however 12 of them were excluded due to unavalability for the second food recall. Final subjects participated in the study was 126 . Minimum total sample size needed was 65 based on calculation to compare differences in fiber intake between two group in several socio-demographic backgrounds using mean and standard deviation (alpha $=0.05,0.8$ power, with reference to previous study by da Silva $\left.{ }^{18}\right)$. Correlation estimation formula was performed to analyze association of independent variables with the fiber intake (alpha of $0.05,0.8$ power, and correlation estimation was 0.3 based on Monsivais and Drewnoski ${ }^{19}$ ) and minimum sample needed was 85. Therefore, total of 126 subjects participated in the study have fulfilled the required minimum sample size. All subjects have signed a written informed-consent before the start of the study. Ethical permission of the study obtained from by Research Ethics Committee, Faculty of Medicine, Universitas Indonesia and Dr. Cipto Mangunkusumo General Hospital. Additional study permission also obtained from Department of Health and Pelayanan Terpadu Satu Pintu (PSTP) of Jakarta province.

\section{Data collection}

Field enumerators were recruited to conduct data collection in the field. Selection criteria of the enumerators were based on academic backgrounds and experiences in the field data collection. Training of enumerators was also conducted to standardize the interview protocols and measurement procedures. Before data collection, pre-testing was conducted to give better understanding in each items questionnaire and avoiding leading questions. Revision to interview flow and adjustment with field conditions were taken into the final study protocols.

\section{Dietary assessment}

Main variable of fiber intake of the respondent were assessed based on 2 days repeated 24-hour food recall measured on non-consecutive days include weekday and weekend. The first dietary recall was conducted in face to face interview in the health center and food photograph book were used to help subjects remembering and estimating the portion consumed. Second dietary recall was performed by phone in non-consecutive day. Analysis on total number of dietary intakes consumed was conducted using Nutrisurvey version 2007 and Excel Office 2010. Database of the fiber content were derived from US Department of Agriculture (USDA), Food and Agriculture Organization (FAO), and Indonesian food database from SEAMEO-RECFON food database. Using similar databases, vegetable fiber and fruit fiber intake were calculated manually using Excel Office 2010. Vegetable and fruit group classification were obtained based on USDA food group components. ${ }^{9}$ Current study also measure total energy intake of the subjects and presented based on percentage of adherence to the Indonesian RDA.

\section{Socio-demographic characteristics assessment}

Socio-demographic characteristics measured were age, sex, marital status, education, and income that were interviewed based on structured questionnaire. Age variable were categorized as early elderly (60 75 years) or older elderly ( $>75$ years). Sex measured based on identification card (ID) classified as male or female. Marital status was classified as married/ lives with partner or widowed/ separated. Education were measured based on the last diploma obtained by subjects and classified using indicators of nine years compulsory education by Indonesian government. Income was categorized based on provincial minimum wage in Jakarta in 2020 (4.2 million Rupiah, currency level at USD $1=$ IDR $14,732) .{ }^{20}$

\section{Statistical analysis}

Data analysis performed using SPSS Statistic ver. 20.0 (IBM Corporation, Armonk, NY, USA). Data on fiber intake in different socio-demographic group 
presented presented as mean (standard deviation) for normally ditributed data, while those without normal distributions were presented as median (25th percentile -75 th percentile). We analyzed the difference amount of total fiber, vegetable fiber, and fruit fiber intake in different socio-demographic settings using Mann-Whitney or independent t-test with CI $95 \%$ and significant level $\mathrm{p}<0.05$. Correlation between continues variable were analyzed using Spearman's correlation. Association of independent variables with total fiber, vegetable fiber, and fruit fiber intake analyzed using linear regression test with CI 95\% and significant level at $\mathrm{p}<0.05$.

\section{Results}

Dietary fiber intake in different socio-demographic settings

Total fiber intake among study subjects were 6.6 g/day $(4.5-10.1)$. The average score was not accomplishing the RDA for elderly population group. Number of subjects that have at least $80 \%$ adherence with the RDA were only $1.6 \%$ (2 subjects), while intake of total fiber 98.4\% (124) subjects were below $80 \%$ RDA. Intake of vegetable and fruit fiber among subjects was $2.5 \mathrm{~g} /$ day and 1.1 $\mathrm{g} /$ day respectively. Based on the socio-demographic backgrounds, lower total fiber intake was found among female, widowed/divorced subjects, lower education and income group, and have $<80 \%$ RDA of energy intake $(p<0.05$ or $p<0.01)$. The pattern on vegetable fiber showed similar result with the total fiber intake. While for fruit fiber, significant higher intake was found among high educated and income level group only $(p<0.01)$. Distribution of dietary fiber intake based on socio-demographic background of the subjects was presented in Table 1.

\section{Factors associated with dietary fiber}

Using Spearman's correlation test, we found that income and energy intake variables were correlated with total fiber intake among subjects. The coefficient correlation for income was $0.34(\mathrm{p}=0.00)$ and energy intake was $0.65(\mathrm{p}=0.00)$. After adjustment with sex, marital status, and education in linier regression analyses, the association were remained with adjusted $\beta$ for income was $0.20(95 \%$ CI $0.00-0.00, p=0.01$ and adjusted $\beta$ for energy intake was $0.65(95 \%$ CI $0.00-0.00, p=0.00)$. For vegetable fiber intake, income and energy intake were variables that showed significant correlation and the correlation coefficient was $0.22(\mathrm{p}=0.01)$ and $0.43(\mathrm{p}=0.00)$ respectively. However, in the linear regression analyses, association of income variable was change (adjusted with age, sex, marital status, and education), thus energy intake was the only variable remained associated with vegetable fiber intake (adjusted $\beta$ 0.47, 95\% CI $0.00-0.00$, $\mathrm{p}=0.00$ ). Variable of fruit fiber showed significant correlation with income $(\mathrm{r}=0.3, \mathrm{p}=0.00)$ and energy intake $(r=0.29, p=0.00)$ in the bivariate analyses. Variable of income was the only factor remained associated with fruit fiber intake in the linier regression analyses (adjusted $\beta 0.41,95 \%$ CI $0.00-$ $0.00, p=0.00$ ) after adjustment with marital status and education. Analyses of associated factors with total fiber, vegetable fiber, and fruit fiber intake were summarized in Table 2.

\section{Discussion}

Dietary fiber intake among subjects in current study was lower compare to study by Setiati et al among outpatient elderly in 15 referral hospital across Indonesia with average fiber intake was about 9 grams. ${ }^{12}$ The result were also lower compare to study among rural elderly in Yogyakarta and community elderly in Hong Kong that showed dietary fiber intake was around 8 grams/ day. ${ }^{13,21}$ Average intake of total fiber among subjects were only accomplishing $34 \%$ than recommended intake in male subjects and $26.3 \%$ among female subjects. Inadequate intake of fiber among elderly were faced both in developing and developed country. Country such as Canada and US reported that average intake of fiber among elderly was 14-15 g/ day and thus still not met it's country dietary recommendation. ${ }^{11}$ It is suggested that high intake of low fiber content grains such as rice and cooking method like frying would related to the lower intake of total fiber. ${ }^{10,18}$ Majority of total fiber intake were contributed from grains, especially whole grains $(50 \%)$, while vegetables were contributed around $30-40 \%$, then followed by fruit $(16 \%)$, and $3 \%$ were from other 
minor sources such as nuts and seeds. ${ }^{10}$ However, as most of Indonesian people were using rice as main staple grains, thus contribution to total fiber intake resulted as poor due to low fiber content in this food source.

Regarding gender differences in total and vegetable fiber intake, this study findings were contrary compare to study among elderly in Lebanon that reported that women showed significant better dietary fiber intake than men (9.6 vs $11.6 \mathrm{~g} / 1000 \mathrm{kcal}){ }^{22}$ However, study among high income settings among elderly in UK Biobank data reported similar findings with current study where dietary fiber intake were found to be higher in male subjects. It was reported that women consume more fat, saturated fat, and carbohydrate as the contribution to total energy, thus it could dominating the contribution of fiber sources food consumption in the diet. ${ }^{23}$ Another similar result were reported among adults in Philippines where deficiency in dietary fiber and important nutrients (vitamin C, vitamin A, calcium, iron) was higher among females. Food pattern such as low consumption in nutrient-dense food like fruit and vegetables were being highlighted need to be improved especially among elderly, females, and those in low SES. ${ }^{24}$ In addition, women were reported have lower diet quality score that mainly contributed from lower variety score and adequacy to dietary fiber, iron, and calcium intake. ${ }^{25}$ Similar gender difference was found in vegetable fiber intake among subjects. The possible explanation was contributed from higher adherence in fruit and vegetable intake recommendation in males than females especially among adults population that were maintained into dietary habit in older life. ${ }^{26}$

A social and psychological factor contributes to many health outcomes among elderly population. Dietary pattern was reported to be influenced by factor such as support from family member and feeling of being wanted in the community and the family. ${ }^{27}$ In current study, elderly that live with partner or married had better total and vegetable fiber intake than those live single/divorced/widowed. This result was compatible with study among Hong Kong Chinese elderly. It was suggested that having partner or family member at home contributes to better control of nutrition intake such as fiber, calcium, and vitamin $\mathrm{D}$ in relation with controlling possible existing diseases condition. ${ }^{21}$

Studies reported that socioeconomic factors such as education and income positively associated with fiber intake both in adult and elderly population. ${ }^{18,21,28}$ According to socioeconomic backgrounds, better income and educated subjects showed higher mean of dietary fiber consumption. The condition was similarly reported among Malaysian urban elderly where nutrition knowledge and purchasing choices in low SES settings could attenuated the dietary pattern intake and resulted in decrease consumption of high fiber food consumption such as fresh fruit and vegetables. ${ }^{29}$ Current study findings were in accordance with previous study where higher education and income were the factors that showed significant difference in total, vegetable, and fruit fiber intake. Better education were associated with access to information level and better lifestyle choice that resulted in higher total energy and fiber intake among individuals. ${ }^{12,28}$ In addition, this study reported that income was variable that associated with total and fruit fiber intake among subjects in the linier regression analyses. There were similar concern reported among adults in Boston, USA study where subjects with higher income reported have higher purchasing power in fiber food sources from fresh products. ${ }^{30}$ This findings emphasize that better access in higher income settings could contributed in better fiber intake among individual.

In addition, better adherence to energy intake among subjects reported to be associated with higher total and vegetable fiber intake in current study. It was contributed from better adherence to energy intake could indicates good compliance with dietary recommendation of the subjects, thus better diet quality that high in fiber consumption could positively affected. ${ }^{26}$ Higher risk to inadequate energy intake were commonly found among elderly. ${ }^{12,21}$ The factors were associated with decrease in several body function such as loss in appetite, difficulties in swallowing, and reduction in nutrient absorption in the body. ${ }^{27}$ These condition might lead to decrease in food intake and weight reduction that usually undetected and could cause serious health problems such as decrease in lean body mass (sarcopenia) or malnutrition. ${ }^{31}$ 
The study reported the most recent evidence of dietary fiber pattern in different socio-demographic backgrounds among elderly live in urban area. By these study findings, appropriate public health intervention in nutrition aspect could be developed in relation to rapid changing in social structure that happen in the urban area. The study performed by validated measurement tools and standardized data collection procedures to ensure data quality administration.

However, there were limitations needed to be considered in current study. First, the using of 24-h recall to measure diet quality might not be representative of dietary intake at the individual level. Despite this limitation, the using of the 24hour dietary recall has been studied to have good reliance to provide accurate estimates of energy and nutrient intake in the population level. ${ }^{32}$ In addition, data collection were administered during COVID-19 pandemic, thus behavioral and dietary changes might occurred. Study conducted in Mainland China sample during lockdown period reported that there were reduction of consumption of fresh food such as fruit and vegetables and physical activity level. ${ }^{33}$ Thus, it may affect to lower the dietary fiber intake compare to general situation before the pandemic. Considering this effect during pandemic situation, comparison of fiber intake with previous studies among Indonesian elderly have showed that prevalence was commonly low. Therefore, the need of improvement in such an emergency situation should be in higher priority. ${ }^{12,13}$

\section{Conclusion}

Low dietary fiber intake was prevalent among subjects in urban area of Jakarta with average intake was $6.6 \mathrm{~g} / \mathrm{d}$. The pattern showed that lower intake found in female, widowed/separated, low education and income, and have inadequate energy intake. Income and energy adequacy were factors that associated with fiber intake among study subjects. By these findings, the study highlighted the need for dietary fiber intake improvement among urban elderly in Jakarta and priority should be considered for those among socially disadvantages group. Further investigation in a larger population need to be conducted in the future studies.

Table 1. Pattern of fiber intake in different socio-demographic backgrounds of the subjects ${ }^{\mathrm{a}}$

\begin{tabular}{|c|c|c|c|c|c|c|}
\hline Variables & $\begin{array}{c}\text { Total fiber } \\
(g / d a y)\end{array}$ & p-value & $\begin{array}{c}\text { Vegetable } \\
\text { fiber } \\
\text { (g/day) }\end{array}$ & p-value & $\begin{array}{c}\text { Fruit fiber } \\
(g / d a y)\end{array}$ & p-value \\
\hline Fiber intake & $6.6(4.5-10.1)$ & & $2.5 \pm 1.6$ & & $1.1(0.0-2.8)$ & \\
\hline$\geq 80 \%$ RDA $(n, \%)$ & $2(1.6)$ & & & & & \\
\hline$<80 \%$ RDA $(\mathrm{n}, \%)$ & $124(98.4 \%)$ & & & & & \\
\hline \multicolumn{7}{|l|}{ Age } \\
\hline Early elderly & $6.6(4.5-10.0)$ & $0.74^{\S}$ & $2.2(1.4-3.3)$ & $0.17 \S$ & $1.1(0.0-2.7)$ & $0.91^{\S}$ \\
\hline Older elderly & $6.4(2.4-11.7)$ & & $3.1 \pm 1.9$ & & $0.7(0.0-3.4)$ & \\
\hline \multicolumn{7}{|l|}{ Gender } \\
\hline Male & $8.5 \pm 3.5$ & $\mathbf{0 . 0 0} * * \S$ & $2.9 \pm 1.6$ & $0.01 * \dagger$ & $1.1(0.0-3.3)$ & $0.27^{\S}$ \\
\hline Female & $5.8(3 . \overline{8}-8.1)$ & & $2.2 \pm 1.5$ & & $0.9(0.0-2.3)$ & \\
\hline \multicolumn{7}{|l|}{ Marital status } \\
\hline $\begin{array}{l}\text { Married/live with } \\
\text { partner }\end{array}$ & $8.2 \pm 3.9$ & $0.00 * * \S$ & $2.5(1.6-3.6)$ & $0.01 * \S$ & $1.1(0.0-3.2)$ & $0.16^{\S}$ \\
\hline Widowed/divorced & $5.8(3.8-7.4)$ & & $2.0 \pm 1.2$ & & $0.7(0.0-2.4)$ & \\
\hline \multicolumn{7}{|l|}{ Education } \\
\hline$\leq 9$ years & $6.4 \pm 3.3$ & $\mathbf{0 . 0 0} * * \S$ & $2.2 \pm 1.3$ & $0.03 * \dagger$ & $0.7(0.0-2.0)$ & $\mathbf{0 . 0 0} * * \S$ \\
\hline$>9$ years & $7.5(5.5-12.1)$ & & $2.8 \pm 1.8$ & & $1.5(0.0-4.4)$ & \\
\hline \multicolumn{7}{|l|}{ Income $^{b}$} \\
\hline $\begin{array}{c}\text { Minimum wage or } \\
\text { higher }\end{array}$ & $11.5 \pm 4.4$ & $0.00 * * \S$ & $3.7 \pm 2.1$ & $0.00 * * \dagger$ & $4.4 \pm 3.5$ & $0.00 * * \S$ \\
\hline $\begin{array}{l}\text { Below minimum } \\
\text { wage }\end{array}$ & $6.3(4.2-9.3)$ & & $2.3 \pm 1.4$ & & $0.9(0.0-2.4)$ & \\
\hline
\end{tabular}




\begin{tabular}{|c|c|c|c|c|c|c|}
\hline Variables & $\begin{array}{c}\text { Total fiber } \\
\text { (g/day) }\end{array}$ & p-value & $\begin{array}{c}\text { Vegetable } \\
\text { fiber } \\
(g / d a y)\end{array}$ & p-value & $\begin{array}{l}\text { Fruit fiber } \\
\quad(g / d a y)\end{array}$ & p-value \\
\hline \multicolumn{7}{|l|}{ Energy intake $^{c}$} \\
\hline$\geq 80 \%$ RDA & $10.6(8.1-12.3)$ & $0.00 * * \S$ & $3.9+2.3$ & $0.00 * * \dagger$ & $1.1(0.7-3.5)$ & $0.28^{\S}$ \\
\hline$<80 \%$ RDA & $6.0(4.0-8.6)$ & & $2.2+1.2$ & & $1.1(0.0-2.6)$ & \\
\hline
\end{tabular}

${ }^{\mathrm{a}}$ Data presented as mean \pm standar deviation; median (25th percentile -75 th percentile); or $\mathrm{n}(\%)$. ${ }^{\mathrm{b}}$ Provincial minimum wage of Jakarta in 2020 is IDR 4,267,000 (USD 300; currency level at USD 1 = IDR 14,732). ${ }^{\circ}$ Based on Indonesian Dietary Guideline (IDG) for age $65-80$ years. 'Independent t-test. ${ }^{\S}$ Mann-Whitney test. *significant level at $\mathrm{p}<0.05 .{ }^{*}$ significant level at $\mathrm{p}<0.01$.

Table 2. Associated factors of fiber intake among study subjects ${ }^{\mathrm{d}}$

\begin{tabular}{|c|c|c|c|c|c|}
\hline Variables & Unadjusted $\beta^{\dagger \dagger}$ & p-value & Adjusted $\beta$ & $95 \% \mathrm{CI}$ & p-value \\
\hline \multicolumn{6}{|l|}{ Total fiber } \\
\hline Sex & & & 0.09 & $-0.52-2.02$ & 0.24 \\
\hline Marital status & & & -0.09 & $-1.99-0.47$ & 0.22 \\
\hline Education & & & 0.06 & $-0.65-1.66$ & 0.39 \\
\hline Income $^{c}$ & 0.34 & $0.00 * *$ & 0.20 & $0.00-0.00$ & $0.01 *$ \\
\hline Energy intake ${ }^{\mathrm{d}}$ & 0.65 & $0.00 * *$ & 0.56 & $0.00-0.00$ & $0.00 * *$ \\
\hline \multicolumn{6}{|l|}{ Vegetable fiber } \\
\hline Age $^{\mathrm{b}}$ & 0.10 & 0.25 & 0.11 & $-0.01-0.08$ & 0.13 \\
\hline Sex & & & 0.09 & $-0.32-0.93$ & 0.34 \\
\hline Marital status & & & -0.14 & $-1.04-0.17$ & 0.16 \\
\hline Education & & & 0.02 & $-0.47-0.65$ & 0.75 \\
\hline Income $^{c}$ & 0.22 & $0.01 *$ & 0.07 & $0.00-0.00$ & 0.41 \\
\hline Energy intake ${ }^{\mathrm{d}}$ & 0.43 & $0.00 * *$ & 0.47 & $0.00-0.00$ & $0.00 * *$ \\
\hline \multicolumn{6}{|l|}{ Fruit fiber } \\
\hline Marital status & & & 0.03 & $-0.5-0.88$ & 0.66 \\
\hline Education & & & 0.10 & $-0.03-1.17$ & 0.25 \\
\hline Income $^{c}$ & 0.30 & $0.00 * *$ & 0.41 & $0.00-0.00$ & $0.00 * *$ \\
\hline Energy intake $^{\mathrm{d}}$ & 0.29 & $0.00 * *$ & 0.09 & $0.00-0.00$ & 0.25 \\
\hline
\end{tabular}

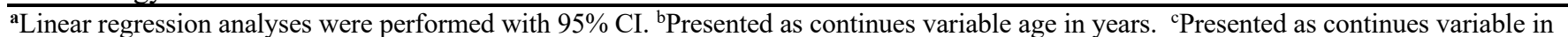

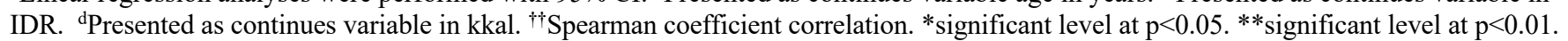

\section{Acknowledgments}

This study was partially funded by University of Indonesia under PUTI Q4 Program 2020. The authors were grateful to support given from Department of Health at Provincial and municipalities" level of DKI Jakarta, also head and staff of each health center. None of the authors reported conflict of interest related to the study.

\section{Conflict of Interest}

Authors declared no conflict of interest regarding this article.

\section{Open Access}

This article is distributed under the terms of the Creative Commons Attribution 4.0 International Licence

(http://creativecommons.org/licenses/by/4.0/), which permits unrestricted use, distribution, and reproduction in any medium, provided you give appropriate credit to the original author(s) and the source, provide a link to the Creative Commons license, and indicate if changes were made.

\section{References}

1. Kementerian Kesehatan RI. Situasi lansia di Indonesia tahun 2017: Gambar struktur umur penduduk Indonesia tahun 2017. Pusat Data dan Informasi. 2017. 
2. Badan Pusat Statistik. Angka harapan hidup menurut provinsi, 1996-2013. 2018.

3. Badan Pusat Statistik. Ketimpangan pengeluaran penduduk Jakarta di atas ketimpangan Nasional sejak 2014. 2019.

4. Tavares RE, Jesus MCP de, Machado DR, Braga VAS, Tocantins FR, Merighi MAB. Healthy aging from the perspective of the elderly: an integrative review. Rev Bras Geriatr e Gerontol. 2017;20(6):878-89.

5. Koga T, Oshita Y. Ageing and health. Vol. 375, The Lancet. 2010. p. 25-6.

6. Fujii H, Iwase M, Ohkuma T, Ogata-Kaizu S, Ide $\mathrm{H}$, Kikuchi $\mathrm{Y}$, et al. Impact of dietary fiber intake on glycemic control, cardiovascular risk factors and chronic kidney disease in Japanese patients with type 2 diabetes mellitus: The Fukuoka Diabetes Registry. Nutr J. 2013;12(1):1-8.

7. Kim CS, Byeon S, Shin DM. Sources of dietary fiber are differently associated with prevalence of depression. Nutrients. 2020;12(9):1-14.

8. Alfawaz H, Khan N, Alhuthayli H, Wani K, Aljumah MA, Khattak MNK, et al. Awareness and knowledge regarding the consumption of dietary fiber and its relation to self-reported health status in an adult arab population: A cross-sectional study. Int $\mathrm{J}$ Environ Res Public Health. 2020;17(12):1-18.

9. Marlett J, Cheung T. Database and quick methods of assessing typical dietary fiber intakes. Vol. 1151, Journal of the American Dietetic Association. 1997. p. 1139-48.

10. Dhingra D, Michael M, Rajput H. Dietary fibre in foods: a review. J Food Sci Technol. 2012;49(June):255-66.

11. Kementerian Kesehatan RI. Peraturan Menteri Kesehatan Republik Indonesia nomor 28 tahun 2019 tentang angka kecukupan gizi yang dianjurkan untuk masyarakat Indonesia. Kementerian Kesehatan RI 2019.

12. Setiati S, Harimurti K, Dewiasty E, Istanti R, Mupangati YM, Ngestiningsih D, et al. Profile of food and nutrient intake among Indonesian elderly population and factors associated with energy intake: a multi-centre study. Acta Med Indones. 2013;45(4):265-74.

13. Arjuna T, Soenen S, Hasnawati RA, Lange K, Chapman I, Luscombe-Marsh ND. A crosssectional study of nutrient intake and health status among older adults in Yogyakarta Indonesia. Nutrients. 2017;9(11).

14. Donini LM, Savina C, Cannella C. Nutrition in the elderly: role of fiber. Arch Gerontol Geriatr. 2009;49 Suppl 1(December):61-9.
15. Dubowitz T, Heron M, Bird CE, Lurie N, Finch BK, Basurto-Dávila R, et al. Neighborhood socioeconomic status and fruit and vegetable intake among whites, blacks, and Mexican Americans in the United States. Am J Clin Nutr. 2008;87(6):1883-91.

16. Storey M, Anderson P. Income and race/ethnicity influence dietary fiber intake and vegetable consumption. Nutr Res. 2014;34(10):844-50.

17. BPJS Kesehatan. Executive summary: program management report and financial report on the JKN program 2014. 2015.

18. da Silva GM, Durante ÉB, de Assumpção D, de Azevedo Barros MB, Corona LP. High prevalence of inadequate dietary fiber consumption and associated factors in older adults: A populationbased study. Rev Bras Epidemiol. 2019;22:1-13.

19. Monsivais P, Drewnowski A. Lower-energydensity diets are associated with higher monetary costs per kilocalorie and are consumed by women of higher socioeconomic status. J Am Diet Assoc. 2009;109(5):814-22.

20. Pemerintah Provinsi DKI Jakarta. Peraturan Gubernur Daerah Khusus Ibukota Jakarta tentang Upah Minimum Sektoral Provinsi Tahun 2020. 2020.

21. Chor JS, Leung J, Griffiths S, Leung $P$. Assessment of malnutrition in community Chinese elderly: A hidden problem in a developed society. ISRN Geriatr. 2013;2013:1-9.

22. Nasreddine L, Chamieh MC, Ayoub J, Hwalla N, Sibai AM, Naja F. Sex disparities in dietary intake across the lifespan: The case of Lebanon. Nutr J. 2020;19(1):1-18.

23. Bennett E, Peters SAE, Woodward M. Sex differences in macronutrient intake and adherence to dietary recommendations: Findings from the UK Biobank. BMJ Open. 2018;8(4):1-7.

24. Angeles-Agdeppa I, Sun Y, Denney L, Tanda K V., Octavio RAD, Carriquiry A, et al. Food sources, energy and nutrient intakes of adults: 2013 Philippines National Nutrition Survey. Nutr J. 2019;18(1):1-13.

25. Abassi MM, El Ati J, Sassi S, Ben Gharbia H, Delpeuch F, Traissac P. Gender inequalities in diet quality and their socioeconomic patterning in a nutrition transition context in North Africa. Rev Epidemiol Sante Publique. 2018;66:S351.

26. McKenzie BL, Santos JA, Geldsetzer P, Davies J, Manne-Goehler J, Gurung MS, et al. Evaluation of sex differences in dietary behaviours and their relationship with cardiovascular risk factors: A cross-sectional study of nationally representative surveys in seven low- And middle-income 
countries. Nutr J. 2020;19(1):1-15.

27. Amarya S, Singh K, Sabharwal M. Changes during aging and their association with malnutrition. $\mathrm{J}$ Clin Gerontol Geriatr. 2015;6(3):78-84.

28. Senia MC, Dharmasena S. Factors affecting the intake of dietary fiber in the United States diet. In: Proceedings of the Southern Agricultural Economics Association's Annual Meeting. 2016. p. 1-24.

29. Shahar S, Vanoh D, Mat Ludin AF, Singh DKA, Hamid TA. Factors associated with poor socioeconomic status among Malaysian older adults: An analysis according to urban and rural settings. BMC Public Health. 2019;19(Suppl 4):112.

30. Senia MC, Dharmasena S. Ascertaining the role of socio-economic-demographic and government food policy related factors on the per capita intake of dietary fiber derived from consumption of various foods in the United States. In: The 2016 Agricultural \& Applied Economics Association Annual Meeting, Boston, Massachusetts. 2016. p. $1-20$.

31. Barkoukis $H$. Nutrition recommendations in elderly and aging. Med Clin North Am. 2016;100(6):1237-50.

32. Conway JM, Ingwersen LA, Moshfegh AJ. Accuracy of dietary recall using the USDA fivestep multiple-pass method in men: An observational validation study. J Am Diet Assoc. 2004 Apr 1;104(4):595-603.

33. $\mathrm{Hu} \mathrm{Z}$, Lin $\mathrm{X}$, Kaminga $\mathrm{AC}, \mathrm{Xu} \mathrm{H}$. Impact of the COVID-19 epidemic on lifestyle behaviors and their association with subjective well-being among the general population in Mainland China: Crosssectional study. J Med Internet Res. 2020;22(8):110 . 